\title{
The geographical characteristics of Nansha Islands in the South China Sea
}

\author{
JIANG Huiping ${ }^{1,2,3}$, 'SU Fenzhen ${ }^{1,3}$, ZHOU Chenghu $^{1}$, YANG Xiaomei ${ }^{1}$, \\ WANG Qi ${ }^{1,2,3}$, CHENG Fei ${ }^{1,3,4}$ \\ 1. State Key Laboratory of Resources and Environmental Information System, Institute of Geographic Sciences \\ and Natural Resources Research, CAS, Beijing 100101, China; \\ 2. University of Chinese Academy of Sciences, Beijing 100049, China; \\ 3. China Centre for Collaborative Innovation of South China Sea Studies, Nanjing University, Nanjing 210093, China; \\ 4. Department of Geographic Information Science, Nanjing University, Nanjing 210023, China
}

\begin{abstract}
As is well-known, Nansha Islands in the South China Sea (SCS) are of important strategic position and invaluable ecological value. Therefore, many attentions are paid to either the political and legal aspects of exposed features that matter in the maritime delimitation, or the physical and geographical characteristics of coral reefs that are the predominant structures of these islands. However, it seems that they consistently lose the connection of sciences and humanities in the research of Nansha Islands in the SCS. In this study, we carry out a combinative research, based on remote sensing data using satellite imagery analysis together with historical materials using literature investigation, so as to reconsider to the geographical characteristics of Nansha Islands from a standpoint of the United Nations Convention on the Law of the Sea (UNCLOS). After thoroughly appraising the statuses of these newly formed sand cays, several high tide features of Nansha Islands are identified. By means of the comparison of satellite images coupled with reference to nautical charting and sailing directions during different time periods, we can conclude that the statuses of these high tide features formed on reef platforms are relatively stable due to the growth of reef-building organisms although their migration patterns are subject to external disturbances, and hence the cursory judgment pursuant to the relevant provisions of the UNCLOS about whether a coral reef belongs to a low tide elevation only based on outdated references or ex parte evidences is not reliable. Moreover, it is accordingly justified to improve further development and perfection of the maritime legislation by eliminating such ambiguities with the growth of coral reefs and the evolution of sand cays being both taken into account.
\end{abstract}

Keywords: coral reefs; sand cays; South China Sea; Nansha Islands; geographical characteristics; UNCLOS

\section{Introduction}

The South China Sea (SCS) $\left(3^{\circ} 37^{\prime}-11^{\circ} 55^{\prime} \mathrm{N}, 109^{\circ} 43^{\prime}-117^{\circ} 47^{\prime} \mathrm{E}\right)$ is a semi-enclosed marginal

Received: 2017-10-31 Accepted: 2017-12-07

Foundation: Strategic Priority Research Program of the Chinese Academy of Sciences, No.XDA13010401

Author: Jiang Huiping (1990-), PhD Candidate, specialized in the research on applications of remote sensing and geographical information system. E-mail: jianghp@lreis.ac.cn

*Corresponding author: Su Fenzhen (1972-), PhD and Professor, E-mail: Sufz@1reis.ac.cn 
sea and runs approximately from the northeast to the southwest, which connects the Pacific Ocean and the Indian Ocean through water channels and straits (Zhao et al., 2011). Xisha Islands, Dongsha Islands, Zhongsha Islands and Nansha Islands make up all of the islands in the SCS, where Nansha Islands are situated in the southernmost tip and have the largest number and variety of island distributions. The predominant structures of Nansha Islands are coral reefs, islands, cays, shoals, etc. Among these geographical features, islands and cays are low-lying and mostly formed on the coral reef flats or infilled lagoons, which have an elevation of ranging from $1.0 \mathrm{~m}$ to $3.0 \mathrm{~m}$ (Kayanne, 2016). The accumulations are mainly composed of coral sand and gravel and stand above water at low or high tide, which are produced by reef-building organisms such as hermatypic corals and zooxanthellae (Perry et al., 2011).

It is generally known that Nansha Islands are of important strategic position and invaluable ecological value, and they are thus the study area of researchers from different countries and specializing in different fields. For a long time, the political and legal aspects have been described and analyzed because of the existence of Nansha Dispute (Marius, 2001; Yang, 2012; Beckman et al., 2014; Loja, 2016; Mou et al., 2016; Yao, 2017). More attention is recently paid to the physical and geographical characteristics of the coral reefs of Nansha Islands due to global change (Yu, 2000; Zu et al., 2008; Yu, 2012; Yu et al., 2014; Zuo et al., 2015) and the advancement of remote sensing (Pan et al., 2002; Hu et al., 2014; Duan et al., 2016; Hsiao et al., 2016; Zhu et al., 2016). However, it should be noted that there are few comprehensive researches that combine the legal and geographical investigation of Nansha Islands with an exception of several researchers' work (Owen et al., 2012; Schofield, 2013; Yamamoto et al., 2014; Schofield, 2015; Tang et al., 2016). Through reconsidering to the geographical characteristics of Nansha Islands from a standpoint of the United Nations Convention on the Law of the Sea (UNCLOS), we can bridge this huge gap.

In the terminology of the UNCLOS, "a feature that is exposed at low tide but covered with water at high tide is referred to as a low tide elevation and those features that are above water at high tide are referred to generically as islands." Accordingly, the exposed and submerged conditions of coral reefs will determine the very entitlements to maritime zones that they can generate. For example, the sand cays with the formation of high tide features, which have the potential to develop into islands to support human survival, can possess the full entitlements to maritime zones, i.e. they are capable of generating $12 \mathrm{n}$ mile territorial zone together with $200 \mathrm{n}$ mile exclusive economic zone pursuant to the UNCLOS. Consequently, it can play an important role both strategically and economically to identify the newly formed sand cays of Nansha Islands in the SCS and appraise their statuses at high tide from the perspective of development.

In this study, we identify such high tide features based on remote sensing data using long time serial satellite imagery analysis. Meanwhile, the exposed and submerged conditions of these coral reefs are thoroughly appraised by referring to historical materials including nautical charting and sailing directions in ancient times when remote sensing data are not available. In Nansha Islands, the new sand cays are mainly found to be formed on the reef platforms of Anda Reef, Qiongtai Reef and Nanxun Reef (North). Furthermore, the growth of coral reefs with vulnerability, the evolution of sand cays with variability and the ambiguities of the UNCLOS with inadaptability are analyzed. 


\section{Study area}

More than 200 reefs, islands, cays and shoals make up the major part of Nansha Islands in the SCS as shown in Figure 1. With a total water surface coverage of roughly $82.3 \times 10^{4} \mathrm{~km}^{2}$, Nansha Islands stretch approximately $897 \mathrm{~km}$ from the north end (Xiongnan Reef) to the south end (Zengmu Shoal), and approximately $916 \mathrm{~km}$ from the east end (Haima Bank) to the west end (Wan'an Bank) (Gao and Liu, 2009). China is the first country to discover, name, develop and administer Nansha Islands and has indisputable sovereignty over these islands and their adjacent waters, which is verified by substantial historical and jurisprudential evidences.

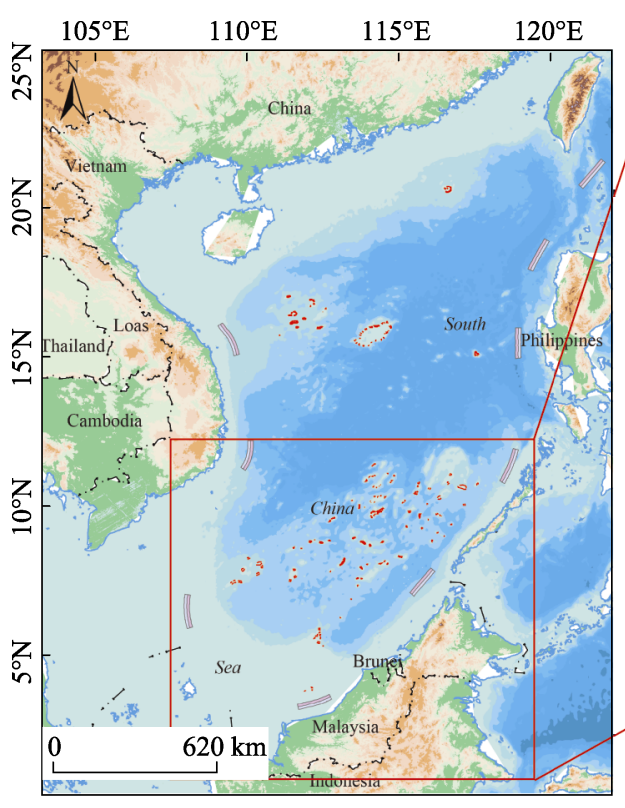

Figure 1 The location of Nansha Islands (Duan et al., 2016)

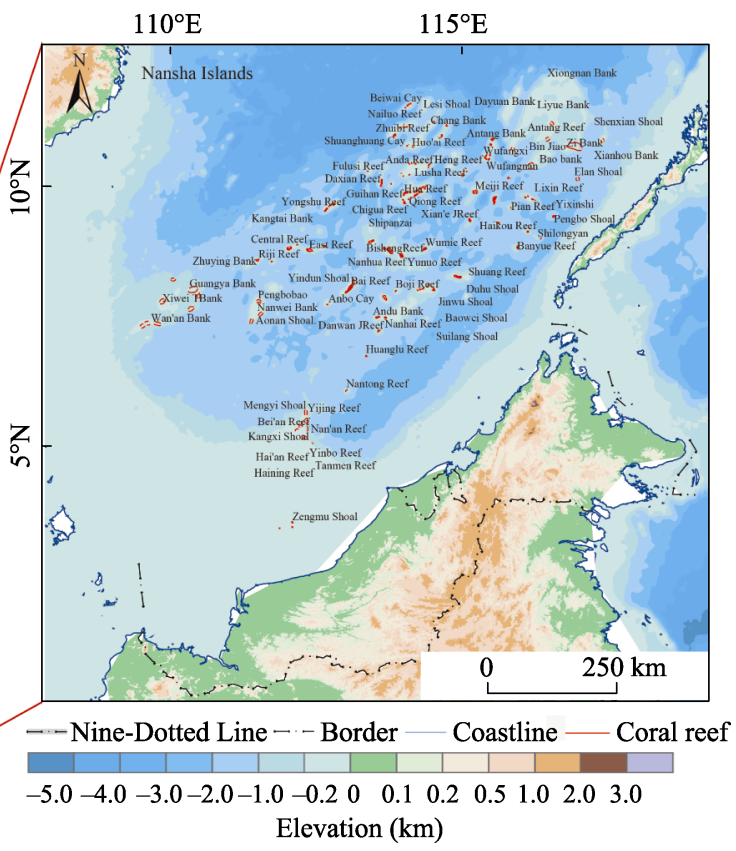

Elevation $(\mathrm{km})$

Being affected by the tropical monsoon climate of the SCS, Nansha Islands are dominated by the southwest monsoon from May to September and the northeast monsoon from November to the next March (Zhao, 1996). The tidal pattern in Nansha Islands is characterized by a diurnal tide. Statistics from the tide station near Yongshu Reef indicate the average tidal range with a fluctuation of $0.5-1.0 \mathrm{~m}$, and the maximum tidal range is $2.0 \mathrm{~m}$ with a possible maximum tidal range of 3.0-4.0 $\mathrm{m}$ (Yu, 2000). Other tidal data available also indicate that mean tidal patterns and ranges are basically consistent across the different features of Nansha Islands in the SCS, although some minor differences exist apparently in tidal intervals.

\section{Materials and methods}

In order to correctly distinguish among the sand cays or islands that stand still above water at high tide, the reefs that are only uncovered with water at low tide and the shoals or banks that remain always submerged during a certain time period, it is necessary to draw a relatively accurate conclusion based on the credible materials available using all kinds of prac- 
tical methods. The method of satellite imagery analysis is reliable when simply recognizing the geographical features above the water surface to make a judgment about whether the coral reefs have the exposed features only at a particular point in time. Nevertheless, it is just not enough when differentiating the low tide elevations from the potential high tide features is a must. With regard to a potential high tide feature that awash at the tide range, we can adopt the method of literature investigation to judge whether it is steadily exposed at high tide over a long period of time by referring to the existing historical materials that are authentic and authoritative. Such literatures include but are not limited to nautical charting, sailing directions, scientific investigation and observation, etc.

\subsection{Remote sensing data used}

A variety of remote sensing data are used in the present analysis. These include Landsat and DigitalGlobe family imagery which are drawn from differing timeframes with a range of resolutions. Among them, Landsat-5 TM, Landsat-7 ETM+, and Landsat-8 OLI multi-spectral imagery have a moderate spatial resolution of $30 \mathrm{~m}$, and QuickBird, GeoEye, and WorldView series satellite imagery have a high ground resolution with the range of $0.3-1.0 \mathrm{~m}$.

\subsection{Satellite imagery analysis}

All scenes of satellite imagery used here are cloud-free or partly cloudy, and then we conventionally project them to the Universal Transverse Mercator (UTM) plane coordinates at the World Geodetic System 1984 (WGS84) reference datum. The satellite imagery processing and analysis for all scenes are carried out using ENVI 5.0 and ArcGIS Desktop10.2 software. Apart from radiometric calibrations, atmospheric corrections, geometric corrections and image registrations, we fuse the multispectral and panchromatic data with different methods provided by ESRI so as to take full advantage of both sets of data to enhance the spatial resolution of these images. After being processed through the preliminary treatments, multi-spectral analysis and change detection methods are applied to monitor the exposed and submerged conditions of such new sand cays that are formed on coral reefs over a long period of time.

\subsubsection{Multi-spectral analysis}

The method of multi-spectral analysis makes use of different red, green and blue combinations of whatever aged Landsat long time serial satellite imagery and modern DigitalGlobe high resolution satellite imagery available. The resulting red + green + blue color images provide all sorts of multi-spectral products depending on different band combinations. The "Multi-spectral Analysis Tool" within the ENVI 5.0 software allows for any three band combinations.

Typically, there are six bands exhibiting a variety of spectral signatures in a single Landsat-5 TM scene that can be used in this study (bands 1-5 and band 7 with band 6 not usable for this purpose being a thermal and cannot be combined with the other bands). For example, a combination of band $3+$ band $2+$ band 1 results in the true color photograph, showing waters in blue, vegetation in green, sand cays in white, etc. In contrast, the multi-spectral analysis using a different combination of bands, such as band $7+$ band $5+$ band 1 , can only show the exposed features, meanwhile, no underwater features are shown in this kind of 
false color photograph.

Here it should be noted that the interface between land and sea shown in the true or false color photograph is generally understood to indicate the mean high water (MHW). Being exposed above the MHW for a long time, the water contents of these newly formed sand cays stay low (Duan et al., 2016). Therefore, the reflectance of the dry accumulations of coral sand and gravel is oppositely high, which allows monitoring easily and identifying apparently within a single near-infrared band image as well (Pan et al., 2002).

\subsubsection{Change detection}

In general, we use the method of change detection to identify, describe, and quantify the differences among long time serial remote sensing images of the same scene under different conditions to meet some particular research goals (Lillesand et al., 2000). Since the migration patterns of the newly formed sand cays vary from time to time due to the vulnerability to the external disturbance, in this study, we cannot easily understand the long-term trend of exposure only based on a single or a couple of images. The post-processing change detection method is thus applied to monitor the statuses of coral reefs in different historical periods by comparing a series of multi-source and various resolution remote sensing images (El-Askary et al., 2014; Zhu et al., 2016). Only by this means, can it be soundly backed up by enough evidences to tell apart the low tide elevations and potential high tide features, consequently making a stable sand cay, which remains long-term exposed above water even at high tide, qualified to have the integral entitlement in maritime delimitation.

\subsection{Historical materials referenced}

Due to many complicated reasons, the long-term and in-situ surveys carried out in Nansha Islands are almost non-existent (Duan et al., 2016). The remote sensing images thus prove to be especially valuable in the appraisal and classification of the geographical features that awash at the tide range. Nevertheless, given the historical materials can offer an alternative field investigation and first-hand observations of these features in question, the satellite imagery analysis is, it should be emphasized, not used in isolation but complemented by other sources of hydrographic observation, scientific investigation and geographical information including nautical charts, sailing directions, etc. Therefore, we can conclude that the exposed and submerged conditions of coral reefs at a past point in time when remote sensing images are not available by referring to these authentic and authoritative materials. Besides, a compilation of such materials published by Chinese authority before the founding of the People's Republic of China (PRC) in 1949 is also used for reference in this study (Han et al., 1988).

It is worth mentioning that other historical materials include but not limited to the "Pub. 161 Sailing Directions (Enroute), South China Sea and the Gulf of Thailand (13th ed.)" which was published by United States National Geospatial-Intelligence Agency in 2011, the "China Sailing Directions, South China Sea (A103)" which was published by Navigation Guarantee Department of the Chinese Navy Headquarters in 2011, the "CIA World Factbook, Paracel Islands" which was published by United States Central Intelligence Agency in 2013, the "Admiralty Sailing Directions, China Sea Pilot (NP31), Vol. 2 (10th ed.)" which was published by United Kingdom Hydrographic Office in 2012 and the "Document No. 204, 
South China Sea and Malacca Strait Pilot" which was published by Japan Coast Guard in 2011. Additionally, the corresponding charts published by these countries are used for reference as well.

(1) Hydrographic observation and scientific investigation

In brief, the earliest survey work was undertaken by the British navy between 1862 and 1868. Subsequently, a sustained attention from several countries involved was focused on Nansha Islands. In the 1920s and 1930s, both the British and Japanese navies were intensively engaged in surveying these geographical features in the SCS, although most of the relevant information was not made public well until the end of the Second World War. Meanwhile, allowing for military or political objectives, the French and American navies also undertook the survey work in the 1930s, although to a lesser degree. More recently, the littoral countries surrounding the SCS have been engaged in a new round of surveying to update the geographical information of areas generally adjacent to their coasts. Since the establishment of the PRC, the relevant organizations and institutions started the hydrographic observation dated back to 1955 in Nansha Islands. From the 1980s, the researchers carried out scientific investigation systematically and designedly, and then the government accordingly built an oceanic observation station near Yongshu Reef with an installation of a tide gauge for the Global Sea Level Observing System (GLOSS) in 1987.

(2) Nautical charting and sailing directions

Besides, nautical charting and sailing directions represent a credible record of the direct observation and investigation of the geographical features in Nansha Islands at a past point in time. Conventionally, some large coral boulders and rocks, which are cemented to the platform of a coral reef, have a high degree of stability and can reasonably be expected to remain exposed or submerged over a long period of time. In particular, some more ephemeral features such as sand cays are extremely vulnerable to the storm surge, but they will often reform in the same location where accumulations happen and can also be considered consistent over time to some extent. These nautical charting and sailing directions are thus no less important, provided they are obtained from reliable sources, whose contents as a whole are full, clear and accurate. In this study, we adopt those descriptions of the exposed and submerged conditions of coral reefs in question based on the sailing directions published by Chinese, American, British, and Japanese authorities together with the corresponding nautical charts published by those countries included.

\subsection{Literature investigation}

In general, literature investigation is typically used to search, classify, review, analyze and conclude among a great deal of historical materials for particular purposes, and such literatures are included but not limited to articles, reports, books, charts, tables, etc. In this study, we can shed a light on the long-term change of such newly formed sand cays in Nansha Islands based on the nautical charting and sailing directions while comparing intensively to the hydrographic observation and scientific investigation. On the condition that a variety of remote sensing data and historical materials referenced are available with a high degree of accuracy and credibility, it is possible to monitor the geographical features that awash at the tide range in a longer time series by using the combination of satellite imagery analysis and 
literature investigation methods.

\section{Results}

By means of the comparison of remote sensing images coupled with reference to nautical charting and sailing directions during different time periods, we are capable of identifying the potential high tide features of Nansha Islands that awash at the tide range. Three coral reefs with newly formed sand cays are mentioned here as the case study, namely Anda Reef, Qiongtai Reef and Nanxun Reef (North). The sand cay of Anda Reef appeared in 2000, and the high tide feature has remained exposed at the tidal range until now in spite of the variation of its migration patterns. The sand cay of Qiongtai Reef was identified in 2004, and the high tide feature has turned into an island since then in view of the survival of a coconut tree. For Nanxun Reef (North), the earliest formation of its sand cay can date back to the 1930s according to Japanese survey, and the high tide feature stood steadily above water before the large-scale reclamation in 2013.

\subsection{Anda Reef}

Anda Reef is located at the northeast end of Zhenghe Reefs, which is shaped like a sea horse and has the largest reef platform among the adjacent reefs. It is reported to be a drying reef with a few large rocks and many small boulders that awash at the tidal range. However, there is no exposed sand cay mentioned in the sailing directions. In addition, no reliable evidence in the past showed that the rocks and boulders could stand above water at high tide. Now we can easily identify the newly formed sand cay at the northeast corner of Anda Reef with the help of high resolution satellite imagery acquired in 2016 as shown in Figure 2. The researchers from the Chinese Academy of

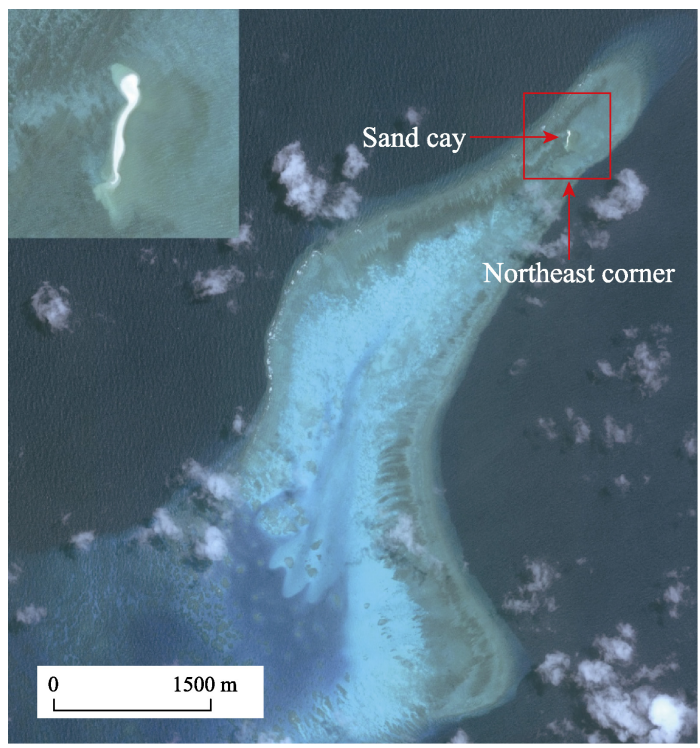

Figure 2 WorldView image of Anda Reef acquired in 2016 (illustrated in true color) Sciences (CAS) arrived at Anda Reef but did not see any exposed features such as sand cays at that time when conducting a scientific investigation in May of 1993 (Zeng et al., 1997; Zhao, 1996). Based on the long time serial remote sensing images as shown in Figure 3, the reef platform of Anda Reef was found to be submerged below water until the calcareous materials began to accumulate at the northeast corner in 1998, and the sand cay could be seen clearly when the accumulations stood above water at the tidal range in 2000 . The topography of such a sand cay is subject to wind and waves because of the monsoon and storm surge, and its migration pattern vary from time to time. Nevertheless, the sand cay recently remains exposed at high tide perennially, and the exposed area increases gradually.

In the case of Anda Reef, the on-going formation of sand cay proves that the accumulation of calcareous materials is a sustainable process. With the exposed area of this sand cay increasing 
progressively and its altitude rising gradually, the high tide feature of Anda Reef will eventually become an island that stands above water at high tide perennially. Therefore, we conclude that the newly formed sand cay of Anda Reef has the potential to turn into an island with the integral entitlement in maritime delimitation.

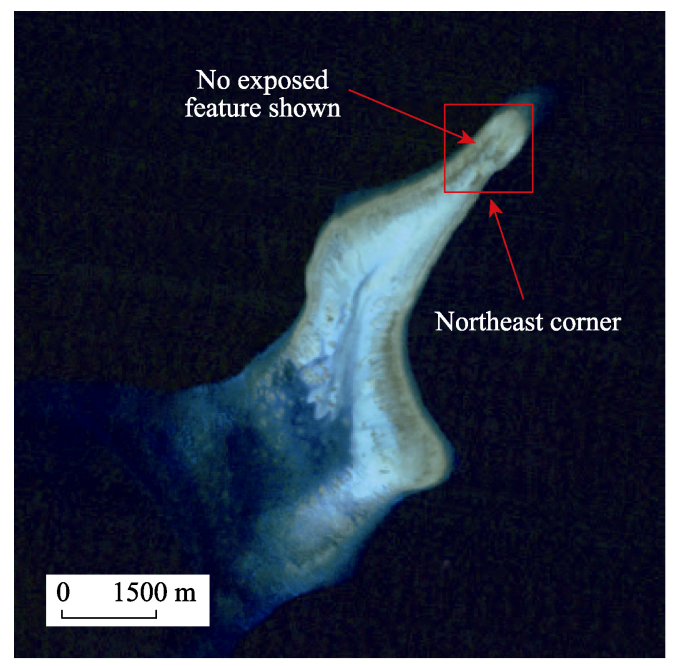

(a) The image acquired in 1997

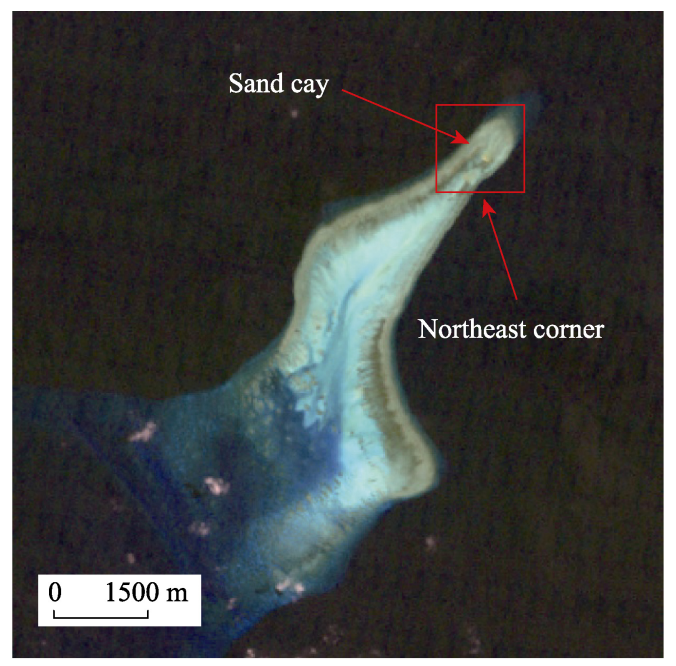

(b) The image acquired in 2000

Figure 3 Landsat-5 TM images of Anda Reef (illustrated in true color)

\subsection{Qiongtai Reef}

Qiongtai Reef is located at the southeast end of the Nankang Shoals $\left(4^{\circ} 41^{\prime}-5^{\circ} 07^{\prime} \mathrm{N}\right.$, $\left.112^{\circ} 28^{\prime}-112^{\circ} 56^{\prime} \mathrm{E}\right)$, which is the only drying coral reef among the adjacent shoals and has a distance of around $120 \mathrm{~km}$ from the Zengmu Shoal. Now we can easily identify the sand cay at the central part of Qiongtai Reef with the help of high resolution satellite imagery acquired in 2016 as shown in Figure 4. Based on the long time serial remote sensing images as shown in Figure 5, we can conclude that the reef platform of Qiongtai Reef was submerged below water before 2002 and the sand cay started to form at the central part in 2004 until the accumulations of coral detritus and bioclast were exposed above water at the tidal range. Since then, the exposed area

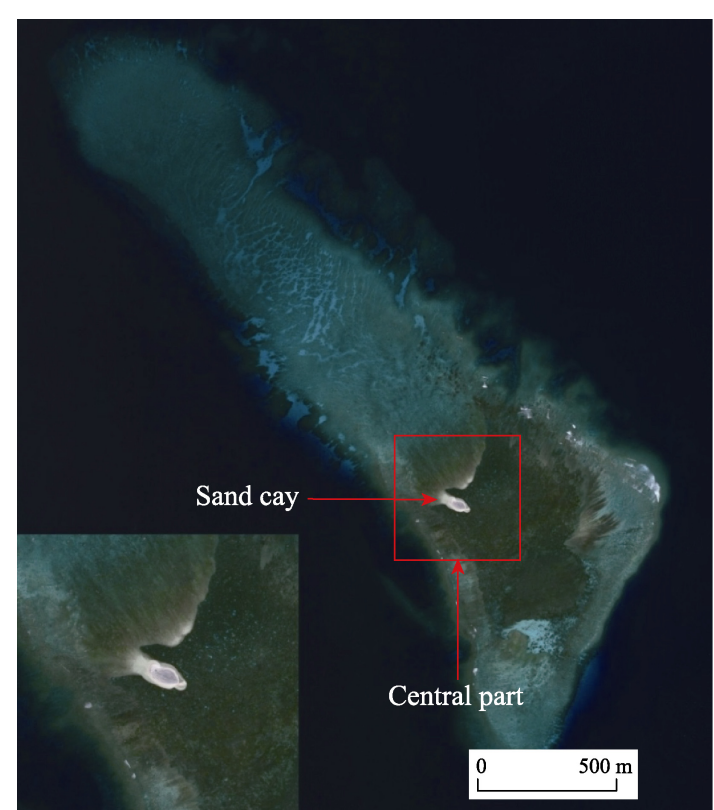

Figure 4 WorldView image of Qiongtai Reef acquired in 2016 (illustrated in true color) of newly formed sand cay increased progressively and its altitude rose gradually year by year. In May of 2010, the researchers from the CAS arrived at Qiongtai Reef when carrying out in-situ surveys as shown in Figure 6, 
and they found that the exposed sand cay formed a circle layer structure with the central part staying low and the peripheral sand ridge standing high (Shan, 2010). Furthermore, it is reported recently that a coconut tree survives in the middle of the exposed area, which means that the freshwater lens is developing at the bottom of such a newly formed sand cay.

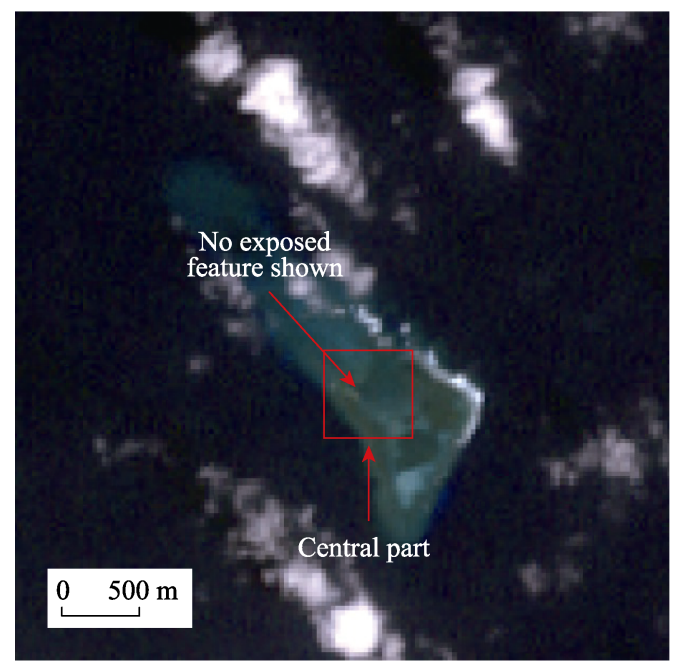

(a) The image acquired in 2002

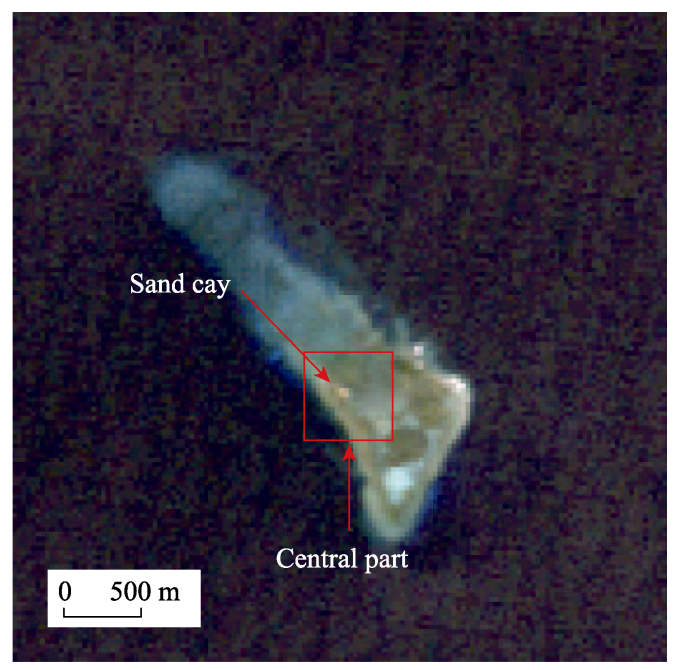

(b) The image acquired in 2004

Figure 5 Landsat-5 TM images of Qiongtai Reef (illustrated in true color)

In the case of Qiongtai Reef, so long as the accumulation of calcareous materials continuously proceeds, the exposed area of sand cay will increase due to the stability of circle layer structure. Therefore, we conclude that the newly formed sand cay of Qiongtai Reef can be referred to as a feature that is above water at high tide, i.e., a high tide feature as an island.
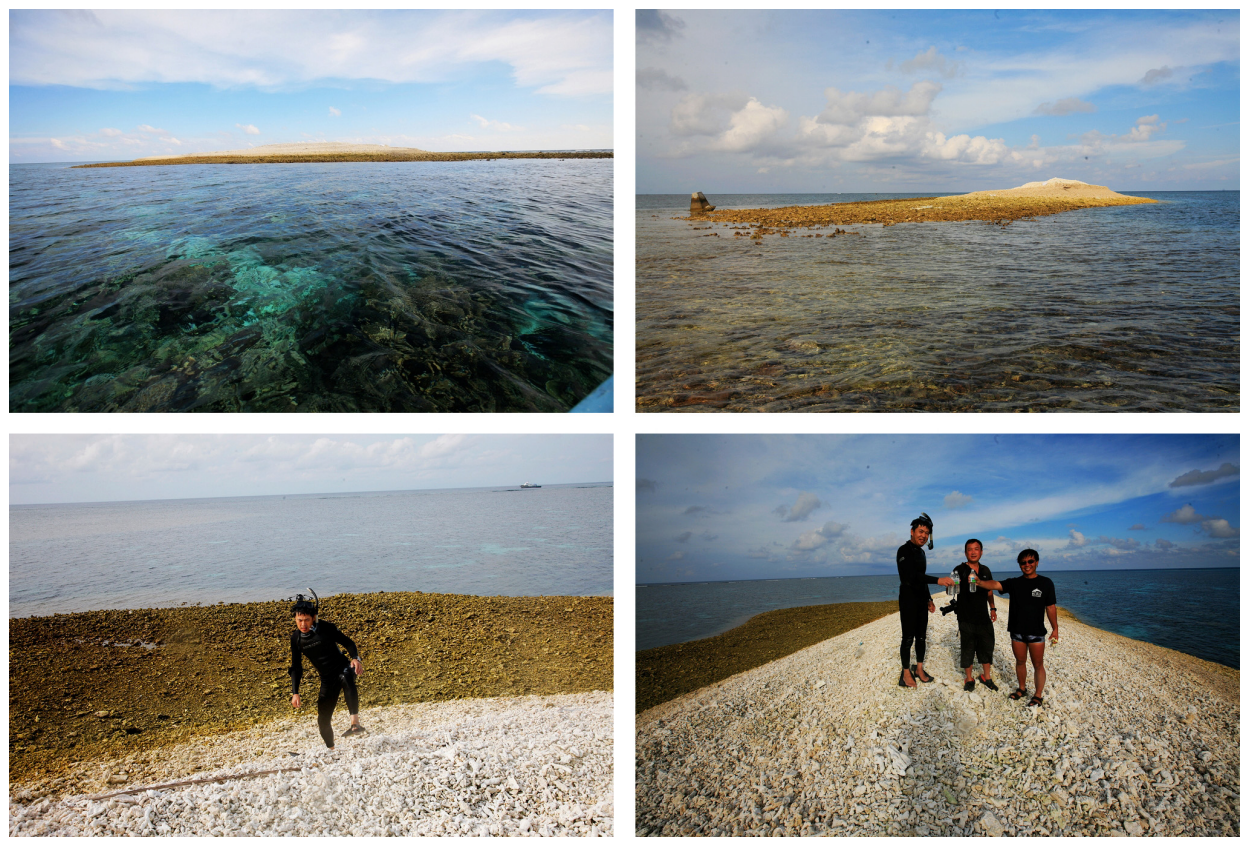

Figure 6 Real scene photos of the sand cay of Qiongtai Reef shot in 2010 (Shan, 2010) 


\subsection{Nanxun Reef (North)}

Nanxun Reef is located at the southwest end of Zhenghe Reefs $\left(10^{\circ} 09^{\prime}-10^{\circ} 25^{\prime} \mathrm{N}\right.$, $\left.114^{\circ} 37^{\prime}-114^{\circ} 49^{\prime} \mathrm{E}\right)$, which consists of two coral reefs with one being situated in the north and one in the south. The coral reef in the north is generically called Nanxun Reef (North), where we can easily identify the exposed sand cay at the northeast corner of reef platform with the support of high resolution remote sensing images acquired in recent years before the large-scale reclamation as shown in Figure 7.

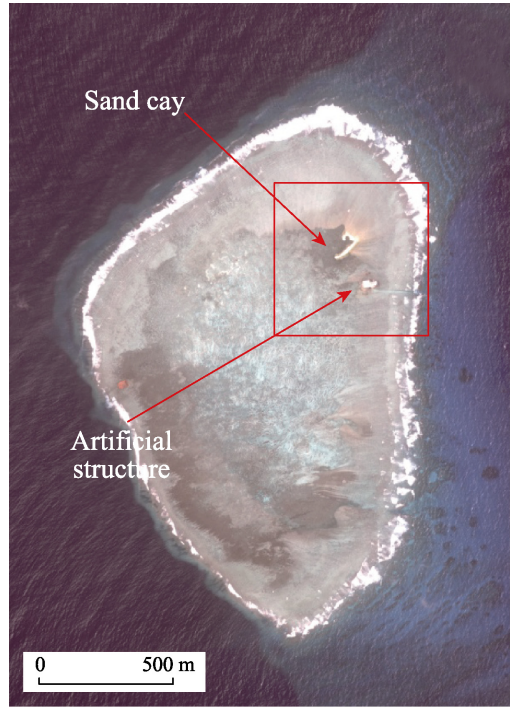

(a) The image acquired in 2011

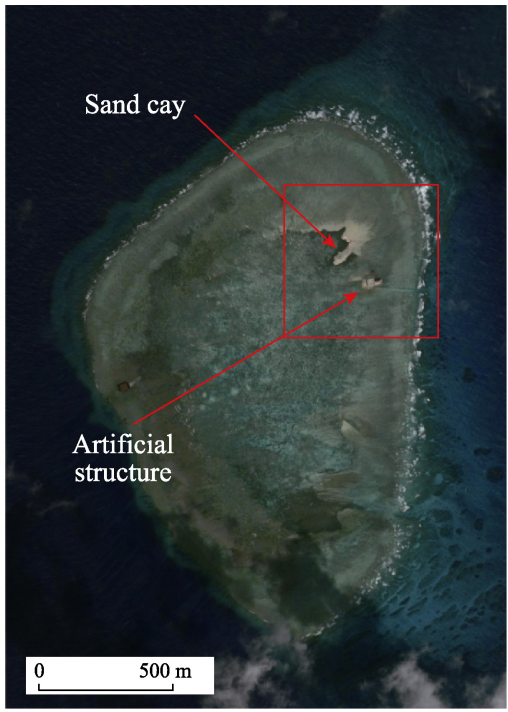

(b) The image acquired in 2012

Figure 7 WorldView images of Nanxun Reef (North) (illustrated in true color)

However, there was not a high tide feature of Nanxun Reef (North) appearing in the earliest sailing directions of Nansha Islands in the SCS (1868 version), and such descriptions remained essentially unchanged throughout various editions published later by the British authorities. Moreover, it should be reminded that the sand cay that stands above water at high tide was not mentioned neither, according to the "China Sailing Directions, South China Sea (A103)" issued by the Navigation Guarantee Department of the Chinese Navy Headquarters in 2011, and it is extremely reasonable to conclude that either the sand cay is a newly formed one in recent years or such a high tide feature is just ignored by mistake for a long time.

Before the Second World War and even during it in the 1930s, Nanxun Reef (North) was also extensively surveyed by the Japanese navy. Conversely, a sand cay was indicated clearly at the northeast corner of Nanxun Reef (North) with a survey marker upon it and the words "height $1.9 \mathrm{~m}$ " in parentheses adjacent to this high tide feature, which was depicted in the large-scale plan of Zhenghe Reefs. The Japanese plan of Zhenghe Reefs was then reproduced and issued as the "U.S. Hydrographic Office Chart No.5659" in 1950 after the war. In 1974 , other survey work was included and the resulting nautical charting was reissued as the “Defense Mapping Agency Chart No.93043" with a magenta overlay depicting some additional details. The accompanying sailing directions describe definitely Nanxun Reef (North) 
as a high tide feature, which is marked by a sand cay with an elevation of about $2 \mathrm{~m}$ at the northeast corner of reef platform.

Concerning the existence of the high tide feature of Nanxun Reef (North), the different descriptions sourced from various nautical charting and sailing directions seem to contradict one another, with the Japanese survey depicting a sand cay at the northeast corner of reef platform in the 20th century whereas the British survey indicating no such a high tide feature in the 19th century. In the view of development, we can consider the high tide feature as a newly formed sand cay in the 20th century, which did not exist in the 19th century. Recently, the exposed area of sand cay increases gradually, although its landform is vulnerable to waves and currents. As a result, we conclude that the formation of the long-standing sand cay of Nanxun Reef (North) can date back to the 1930s and the exposed feature remains above water at high tide for a long time. Given that the growth of coral reefs and the evolution of sand cays, it is definitely reasonable to consider that the high tide feature of Nanxun Reef (North) has the potential to turn into an island with the integral entitlement in maritime delimitation.

\section{Discussion}

The sand cays formed on the reef platform of Nanxun Reef (North), Qiongtai Reef and Anda Reef are composed of coral detritus and bioclast, which leads to an inevitable variability in landforms of the exposed features that stand above water at the tidal range. On one hand, since the on-going growth of coral reefs is a sustainable process, the calcareous materials such as calcium carbonates are produced continuously by reef-building organisms such as hermatypic corals and zooxanthellae. On the other hand, as the accumulation of calcareous detritus and bioclast proceeds, the bare sand cays will go through several stages and turn into green islands that are formed on coral reefs (Zeng et al., 1997; Zhao, 1996). However, the exposed features are low-lying and largely composed of some unconsolidated sediment that can be readily affected by waves and currents, especially the storm surge. Meanwhile, the growing reef-building organisms are subject to the most vulnerable environments in a globally and significantly changed climate setting (Perry et al., 2011; Woodroffe et al., 2008). Therefore, it is a must to appraise the statuses of such newly formed sand cays with the unique geographical characteristics of coral reefs being taken into account when considering their entitlements pursuant to relevant provisions of the UNCLOS. Unfortunately, there are many inherent ambiguities concerning the regime of islands, though the convention sets up the basic legal framework of using and managing sea (Yang, 2012).

\subsection{Coral reef and its growth}

Coral reefs are biogenic reef platforms and the exposed features are composed of calcium carbonates that are mainly produced by the hermatypic corals. The growing rate of reef-building corals is equal to $5-10 \mathrm{~mm} / \mathrm{a}$ with a maximum of $20 \mathrm{~mm} / \mathrm{a}$ and the deposition rate of reef flats is averagely more than $2 \mathrm{~mm} / \mathrm{a}$ (Zhao, 1998). The growing rate of hermatypic corals and the deposition rate of reef flats are accordingly not less than the sum total of crustal subsiding rate $(0.1 \mathrm{~mm} / \mathrm{a})$ and modern sea level rise rate $(1-2 \mathrm{~mm} / \mathrm{a})$ (Zhao et al., 1997; Zhao, 1998). The newly formed sand cays of Nansha Islands are thus stable because of the accumulation of calcareous materials and the increase of exposed areas.

The accompanying sea level and seawater temperature rises induced by climate change 
affect dramatically the growth of corals at the global scale (Woodroffe, 2008). Meanwhile, the process of island formation is correspondingly influenced by global warming through the ecological degradation of reef-building organisms due to thermally induced bleaching (Zuo et al., 2015), which inevitably induces a drop in productivity and the reduction of calcareous materials (Perry et al., 2011; Yamano et al., 2004). In particular, not only affected by the ubiquitous global warming but also disturbed by the intensive anthropogenic activities, the ability of calcification of corals and the consequent production of calcareous materials in the SCS have declined increasingly (Yu, 2014). In general, the coral reefs in the SCS have been experiencing the process of ecological degradation, and the living coral cover dropped up to less than $20 \%$ in much of the study area (Yu et al., 2014). In addition, the geochemical data of coral skeletons acquired from Meiji Reef clearly show that the oceanic acidification happened with the rise of atmospheric $\mathrm{CO}_{2}$ concentrations in the past two centuries, but there is no strong relation between the skeletal calcification and oceanic acidification to be found. Furthermore, the calcification of reef-building organisms responds nonlinearly to the elevated sea surface temperature (SST) in the case of Meiji Reef. In conclusion, the impacts on many coral reefs in Nansha Islands of global warming and the associated environmental change are not explicit, with many evidences indicating that the SST rise boosted the coral growth in the early and mid-20th century but hindered oppositely the coral calcification in recent 20 years (Shi et al., 2012).

\subsection{Sand cay and its evolution}

The evolution process from a bare sand cay to a sand island with vegetation can be divided into three stages. The first stage is that the calcareous materials start to accumulate within a specific area on the reef platform until a high tide feature appears. The second stage is that the exposed area and altitude of the newly formed sand cay increase continuously until a circle layer structure begins to take shape. The third stage is that the freshwater lens starts to develop until the underground water can support the survival of plants with the exposed area of such a sand cay increasing and its altitude rising further. For the coral reefs of Nansha Islands in the SCS, the high tide features formed on the reef platforms are relatively stable due to the growth of reef-building organisms and the accumulation of calcareous materials although the migration patterns of sand cays are subject to external disturbances.

Apart from global climate change, the hydrodynamic disturbance such as high waves from tropical cyclones will cause severe damage to the newly formed sand cays and change readily their landforms above water (Kayanne et al., 2016). Specifically, storm surge is constructive to the accumulations of the coral detritus and bioclast, and the exposed sand cays that can stand still above water at high tide are subsequently formed on the platform of coral reefs, under which there will be freshwater lens developing when the radius of exposed area is more than $300 \mathrm{~m}$ (Zhao, 2005). Additionally, the wind directions and wave transformation also play a key role in promoting the evolution of sand cays above water if the underwater topography of coral reefs remains unchanged (Harris et al., 2015; Shannon et al., 2012; Zhu et al., 2016). The status of coral reef ecosystem, sedimentary characteristics and the impacts of tropical cyclones and sea level change are the most important influencing factors for the maintenance of the new sand cays with high tide features that are formed on reef platforms in Nansha Islands (Zhao et al., 2017). Being affected by the combination of global climate 
change and hydrodynamic disturbance, the migration patterns of such features are difficult to predict in the future. However, since the accumulation of calcareous materials produced by the growing reef-building organisms increases and the on-going sediment transport induced by waves and currents continues, the exposed areas of such high tide features will enlarge progressively with their altitudes rising gradually, and the newly formed sand cays in Nansha Islands will have the potential to turn into green islands with the integral entitlement in maritime delimitation.

\subsection{UNCLOS and its ambiguities}

According to the relevant provisions of the UNCLOS, the term of "high tide" is not defined explicitly and cannot thus be enforced technically, because it has juristically different interpretations from the standpoints of various measurements and water levels. Moreover, no words like "permanently" or "perennially" appear in the articles relating to this question, which means that ephemeral features like the accumulations of coral detritus and bioclast, which are formed on the platform of coral reefs and awash at the tidal range, should be considered as high tide features and thus have the same entitlement as rocks at least, although they are only exposed above water at high tide transitorily. Due to the existence of ambiguities in the relevant provisions of the UNCLOS, the legal statuses of the high tide features such as the newly formed sand cays of Nansha Islands cannot be determined statically. However, the maritime entitlements of islands, rocks and low tide elevations vary greatly in the territorial sea, continental shelf and the Exclusive Economic Zone (EEZ) under the international law of the sea framework (Mou et al., 2016).

Additionally, the dispute concerning the legal statuses of the high tide features such as sand cays or islands is a dispute concerning sovereignty over these coral reefs in essence (Yao, 2017). Therefore, the existing convention cannot be used to solve the sovereignty disputes of Nansha Islands in the SCS to some extent (Yang, 2012). Meanwhile, the cursory judgment pursuant to the relevant provisions of the UNCLOS that a coral reef belongs to a low tide elevation only based on outdated references or ex parte evidences is not convincible and reliable. Above all, when appraising the exposed and submerged conditions of the newly formed sand cays in Nansha Islands according to the UNCLOS, more attentions should be paid to the unique geographical characteristics including the growth of coral reefs and the evolution of sand cays over a long period of time.

\section{Conclusions}

In this study, we identify the newly formed sand cays in Nansha Islands and analyze the exposed and submerged conditions of the calcareous accumulations that are composed of coral detritus and bioclast. Both satellite imagery analysis and literature investigation are used to appraise the statuses of the potential high tide features based on the long time serial remote sensing images coupled with historical materials including nautical charting, sailing directions and other historical materials. For the coral reefs of Nansha in the SCS, it is difficult to differentiate such newly formed sand cays according to the relevant provisions of the UNCLOS, because the exposed areas and altitudes of these high tide features vary from time to time due to the vulnerability to external disturbances. However, the new sand cays formed on the reef platforms will be deemed to have the stability of exposure because of the growth 
of coral reefs and the evolution of sand cays, although their migration patterns are subject to wind, tide, storm surge, etc. Therefore, it is a must to undertake the reconsideration to the geographical characteristics of Nansha Islands from a standpoint of maritime legislation. The main conclusions of this study are summarized in the following three points.

(1) In terms of the UNCLOS, the regime of islands cannot discriminate coral reefs from common rocks, and the obsolete knowledge about islands is wholly built upon the inorganic rocks rather than the biotical reefs with reef-building organisms growing and calcareous materials being produced continuously. As a result, we should pay more attentions to the vulnerability of coral reefs, the variability of sand cays and the inadaptability of maritime legislation from a perspective of development, in light of the growing conditions of coral reefs in question, the evolution process of such newly formed sand cays and the ambiguities of the relevant provisions of the UNCLOS. Meanwhile, we conclude that the reconsideration to the geographical characteristics of coral reefs in Nansha Islands and further improvement of the existing convention can be a solution.

(2) It should be noted again that Nansha Islands are of important strategic position and invaluable ecological value, and those high tide features such as the newly formed sand cays matter a lot in the maritime delimitation. Therefore, we need to give the same emphasis to these exposed area at sea as on land and take measures to protect reef-building organisms such as hermatypic corals and zooxanthellae. However, the island formation process is greatly influenced by the degradation of coral reef ecosystem and the reduction of living coral cover, which inevitably induces a drop in reef-building productivity and a decrease of calcareous materials. As a result, the reinforcement of coral reef environmental monitoring together with ecological restoration admits of no delay.

(3) Overall, with the combination of satellite imagery analysis and literature investigation based on remote sensing data and historical materials, we bridge the huge gap between the geographical and legal aspects in the fields of Nansha Islands research by identifying, analyzing and appraising the statuses of the newly formed sand cays. It is worth mentioning that a new viewpoint of reconsidering to coral reefs in Nansha Islands and the UNCLOS is put forward in this study. Directions for future research includes adopting more diversified remote sensing data to monitor the production of calcareous materials and the evolution of such newly formed sand cays, thus providing scientific and technological support to protect the invaluable reef-building organisms and coral reef ecosystem.

\section{References}

Beckman R C, Schofield C H, 2014. Defining EEZ claims from islands: A potential South China Sea change. International Journal of Marine \& Coastal Law, 29(2): 193-243.

Duan Yuewei, Liu Yongxue, Li Manchun et al., 2016. Survey of reefs based on Landsat 8 operational land imager (OLI) images in the Nansha Islands, South China Sea. Acta Oceanologica Sinica, 35(10): 11-19.

El-Askary H, El-Mawla S H A, Li J et al., 2014. Change detection of coral reef habitat using Landsat-5 TM, Landsat 7 ETM+ and Landsat 8 OLI data in the Red Sea (Hurghada, Egypt). International Journal of Remote Sensing, 35(6): 2327-2346.

Gao Junguo, Liu Baoyin, 2009. The Nansha Islands Spatial Information Fusion Analysis and Warning: Reefs Development Military Regional Warning System. Beijing: China Ocean Press. (in Chinese)

Han Zhenhua, Lin Jinzhi, Wu Fengbin, 1988. Compilation of Historical Materials on the Nanhai Islands of China. 
Beijing: The Oriental Press. (in Chinese)

Harris D L, Vila-Concejo A, Webster J M et al., 2015. Spatial variations in wave transformation and sediment entrainment on a coral reef sand apron. Marine Geology, 363: 220-229.

Hsiao Y S, Hwang C, Cheng Y S et al., 2016. High-resolution depth and coastline over major atolls of South China Sea from satellite altimetry and imagery. Remote Sensing of Environment, 176: 69-83.

Hu Lianbo, Liu Zhen, Liu Zhishen et al., 2014. Mapping bottom depth and albedo in coastal waters of the South China Sea Islands and reefs using Landsat TM and ETM+ data. International Journal of Remote Sensing, 35(11/12): 4156-4172.

Kayanne H, Aoki K, Suzuki T et al., 2016. Eco-geomorphic processes that maintain a small coral reef island: Ballast Island in the Ryukyu Islands, Japan. Geomorphology, 271: 84-93.

Lillesand T M, Kiefer R W, 2000. Remote Sensing and Image Interpretation. New York: Wiley.

Loja M H, 2016. The Spratly Islands as a single unit under international law: a commentary on the final award in Philippines/China Arbitration. Ocean Development \& International Law, 47(4): 309-326.

Marius Gjetnes, 2001. The Spratlys: Are they rocks or islands? Ocean Development \& International Law, 32(2): 191-204.

Mirzaei A, Tangang F, Juneng L, 2015. Wave energy potential assessment in the central and southern regions of the South China Sea. Renewable Energy, 80: 454-470.

Mou Xingyu, Zhang Yancang, 2016. The legal status of island-like features in the South China Sea. The Journal of South China Sea Studies, 2(4): 38-46. (in Chinese)

Owen N A, Schofield C H, 2012. Disputed South China Sea hydrocarbons in perspective. Marine Policy, 36(3): 809-822.

Pan Chunmei, Ding Qian, Cao Wenyu, 2002. TM image analysis of island reef topography of the Nansha Islands. Remote Sensing for Land \& Resources, 14(2): 34-37. (in Chinese)

Perry C T, Kench P S, Smithers S G et al., 2011. Implications of reef ecosystem change for the stability and maintenance of coral reef islands. Global Change Biology, 17(12): 3679-3696.

Schofield C H, 2013. What's at Stake in the South China Sea? Geographical and Geopolitical Considerations. Edward Elgar Publishing.

Schofield C H, 2015. Adrift on complex waters: Geographical, geopolitical and legal dimensions to the South China Sea disputes. South China Sea Maritime Dispute Political Legal \& Regional Perspectives.

Shan Zhiqiang, 2010. A National Marine Park for coral reefs can be established here in Nankang Shoals. Chinese National Geography, (10), 164-179.

Shannon A M, Power H E, Webster J M et al., 2012. Evolution of coral rubble deposits on a reef platform as detected by remote sensing. Remote Sensing, 5(1): 1-18.

Shi Qi, Yu Kefu, Chen Tianran et al., 2012. Two centuries-long records of skeletal calcification in massive Porites colonies from Meiji Reef in the southern South China Sea and its responses to atmospheric $\mathrm{CO}_{2}$ and seawater temperature. Sci. China Earth Sci., 55: 1-12. (in Chinese)

Tang Meng, Ma Jinsong, Wang Ying et al., 2016. Spatial demarcation principles of the Dotted Line in the South China Sea. Acta Geographica Sinica, 71(6): 914-927. (in Chinese)

Woodroffe C D, 2008. Reef-island topography and the vulnerability of atolls to sea-level rise. Global \& Planetary Change, 62(1): 77-96.

Yamamoto L, Esteban M, 2014. Atoll Island States and International Law: Climate Change Displacement and Sovereignty. Berlin: Springer-Verlag, 35-36.

Yamano H, Tamura M, 2004. Detection limits of coral reef bleaching by satellite remote sensing: Simulation and data analysis. Remote Sensing of Environment, 90(1): 86-103.

Yang Zewei, 2012. On non-application of the United Nations Convention on the Law of the Sea for Solution to Disputes of South China Sea. Law Science Magazine, 33(10): 1-8. (in Chinese)

Yao Ying, 2017. On the determination of the status of maritime features in the award of the South China Sea Arbitration: Legal paradox and China's countermeasures. Jilin University Journal Social Sciences Edition, 57(2): 
43-56. (in Chinese)

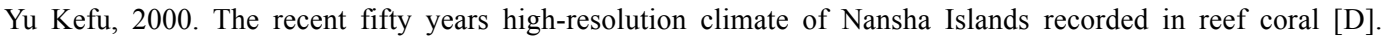
Guangzhou: Guangzhou Institute of Geochemistry, Chinese Academy of Sciences. (in Chinese)

Yu Kefu, 2012. Coral reefs in the South China Sea: Their response to and records on past environmental changes. Sci. China Earth Sci., 55: 1217-1229. (in Chinese)

Yu Kefu, Zhang Guangxue, Wang Ren, 2014. Studies on the coral reefs of the South China Sea: From global change to oil-gas exploration. Advances in Earth Science, 29(11): 1287-1293. (in Chinese)

Zeng Zhaoxuan, Liang Jingfen, Qiu Shijun, 1997. Coral Reefs Geomorphic Research in China. Guangzhou: Guangdong People's Publishing House. (in Chinese)

Zhao Huanting, 1996. Physical Geography of Nansha Islands. Beijing: Science Press. (in Chinese)

Zhao Huanting, 1998. Characteristics of neotectonic movement of coral reef area of the South China Sea Islands. Marine Geology \& Quaternary Geology, 18(1): 37-45. (in Chinese)

Zhao Huanting, Song Chaojing, Sun Zongxun et al., 1997. The evolutionary characteristics of the Holocene coral reefs of the South China Sea islands. Quaternary Sciences, 17(4): 301-309. (in Chinese)

Zhao Huanting, Wang Lirong, 2005. Tsunami and coral reef. Marine Geology Letters, 21(7): 1-3. (in Chinese)

Zhao Huanting, Wen Xiaosheng, Sun Zongxun et al., 1996. The physical characteristics of coral reefs in Nansha Islands. Acta Oceanologica Sinica, 18(5): 61-70. (in Chinese)

Zhao Meixia, Jiang Dapeng, Zhang Qiaomin, 2017. Review on the study of coral cay dynamics and its stability. Tropical Geography, 37(5): 694-700. (in Chinese)

Zhao Ziyu, Shen Sanwei, 2011. The rise and hold, highlighting the strategic position of South China. National Think Tank, (1): 7-12. (in Chinese)

Zhu Haitian, Jiang Xingwei, Meng Xuelian et al., 2016. A quantitative approach to monitoring new sand cay migration in Nansha Islands. Acta Oceanologica Sinica, 35(3): 102-107.

Zu Tingting, Gan Jianping, Erofeeva S Y, 2008. Numerical study of the tide and tidal dynamics in the South China Sea. Deep Sea Research Part I Oceanographic Research Papers, 55(2): 137-154.

Zuo Xiuling, Su Fenzhen, Wu Wenzhou et al., 2015. Spatial and temporal variability of thermal stress to China's coral reefs in South China Sea. Chinese Geographical Science, 25(2): 159-173. 